\title{
China's Regional Disparity in Demographic Transition: A Spatial Analysis ${ }^{+}$
} Jiamin Wang ${ }^{*}$

\begin{abstract}
China's regional income gap has given rise to different socio-economic characteristics of its core and periphery, leading to different expressions in demographic transition. This paper explores the spatial pattern of China's fertility, age, migration, and household transition and finds that the regional pattern of demographic transition roughly follows a gradient of provinces' economic status. Further analysis indicates that this pattern is more sensitive to economic conditions in rural areas than in urban equivalents.
\end{abstract}

Key Words: Regional disparity, demographic transition, fertility transition, age transition, migration transition, household transition.

JEL Classifications: N3, R58, R23

\section{INTRODUCTION}

China's economic reform and opening-up policies, which have been in effect since 1978, initially adopted a "growth center" approach: the coast was given preference over other areas in the hope that it would later stimulate economic growth in lagging areas. After nearly three decades, however, this policy seems to have triggered less of the intended "trickle-down effect" and more of a "polarizing effect." Hence, the income gap has grown between West China, Central China, and the coast.

As a transitional economy, China has been undergoing dynamic socio-economic changes during the last quarter of the $20^{\text {th }}$ century; this in turn has left its mark on the demographic transition of the Chinese population. China's one-child policy, which officially took effect in 1979, has dramatically lowered the overall fertility rate of the country; yet due to China's regional economic disparity, acceptance and compliance with the regulation has been uneven across regions, and the pace of demographic transition has varied spatially as well.

This paper aims to explore China's regional disparity in demographic transition and its relationship with underlying socio-economic factors. The demographic transition, notably the reduction in the fertility rate, has been seen as the prime force in the movement from stagnation to a state of sustained economic growth because it enables economies to convert a larger share of the product from factor accumulation and technological progress into growth of income per capita (Galor 2005). In 2007, China’s gross national income ranked fourth largest in the world; but its economic output is spread across to a very large population-1.3 billion citizens, the most of any country in the world. In 2007, China’s gross national income per capita ranked just 122

\footnotetext{
${ }^{+}$The author is grateful to the editor Michael Lahr, two anonymous referees, and Sandy Dall'erba for their helpful comments and suggestions on earlier drafts of this paper.

*Ph.D. candidate, School of Public Policy, George Mason University, 3401 Fairfax Drive, MS 3B1, Arlington, VA 22201. Email: jwangd@gmu.edu.
} 
among all 200-plus nations of the world, and its purchasing power parity was 5,370 international dollars, which was much lower than the world average of 9,852 (World Bank 2008). There are many different perspectives on the relationship between population and economic growth: the extremes are represented by the traditionally pessimistic “Malthusian Trap” view and Simon's (1992) more positive view that population is the solution to resource scarcities because people and markets innovate, and new technologies will make more resources available. Yet Simon's view does not seem to fit China's situation: China's exceptionally large population continues to pose a serious challenge to the country's resources and to its ability to raise the living standards of its people. Hence a moderate curb on excessive population growth could alleviate many of the resource shortages that China currently faces, as well as allow its people to better enjoy the productivity growth brought by the three decades of economic reform. This paper sheds light on how China's regional disparity in demographic transition has affected the momentum of economic development in each of its major regions. Thus demographic dynamics are linked to the broader issue of the country's economic progress and the spatial distribution of wealth.

The paper is organized as follows. Section 2 reviews literature on demographic transition, especially the fertility transition. Section 3 briefly describes China's economic reform and the consequent regional gap, as well as its population control policy. Section 4 examines the spatial variation in China's demographic transition by looking at statistics related to fertility transition, age transition, migration transition and household transition, and attempts to interpret it in the light of regional socio-economic disparity. Section 5 concludes with policy implications.

\section{LITERATURE REVIEW: DEMOGRAPHIC TRANSITION}

The demographic transition model is generally held to be based on the experiences of the industrialized West. Yet Caldwell (1997) argues that, rather than two fertility transitions-namely, one in the West and one in developing countries - there has been instead a progression of transitions. Thus, he contends that a unified theory exists. Demographic transition is really a set of transitions (Weeks 2005) that unfold as a society progresses through its pre-industrial, transitional, industrial and post-industrial stages. Fertility transition, characterized by a shift from a high natural birth rate to a lower controlled one, is usually a response to growing educational and economic opportunities for women, the availability of contraceptives, and a declining infant mortality rate. Together with the mortality transition, fertility transition facilitates predictable changes in the age structure of the population-age transition-usually articulated via an aging population and a climbing elderly dependency ratio. As the death rate tends to decline in advance of the decline of birth rate (Dyson and Murphy, 1985; Coale, 1987; Easterlin, 1987), an oversupply of labor inevitably arises, at least in rural areas; this, together with the increasing job opportunities in urban areas as the society evolves into the industrial age, brings about a transition in migration, with metropoles as destinations. Via these processes, family sizes shrink and extended families are replaced by nuclear ones, creating a transition in households.

To understand the driving force of demographic transition, it is necessary to look at critical socio-economic dynamics. Particularly, there is a large body of literature that addresses fertility transition. Pritchett (1994) finds that contraceptive access is not a dominant factor in 
determining fertility differences; rather, the challenge of reducing fertility comes from reducing couples' desired birth targets, which are shaped by economic, social, educational, and cultural conditions. Based on Becker's (1981) theoretical model of household economics, children can also be viewed as a type of "consumer goods," and each household aims to maximize its utility function in terms of which goods it can afford: children, child quality, and conventional goods and services. Each family is constrained by parents' time and the cost of purchased goods. As economic well-being improves and income rises, the opportunity cost of raising a child increases with parents' wages. For similar reasons, the cost of child-raising increases also rises whether or not the quality of care improves. Together, the opportunity costs of parenting and the actual costs of child care suppress the fertility rate (Jayaraman, 1995).

The argument for a relationship between fertility and economic growth originated with Malthus (1798), who related population growth to an economy's material conditions, particularly food supply. He postulated that, without restraint, population would increase geometrically, but food production would increase only arithmetically. Thus, while population grows, per capita consumption must necessarily fall and at some point reach a minimum level of required subsistence, forming what has become known as a "Malthusian trap," which puts a further check on population growth. Indeed, Malthus' bold proposition was apparently sufficiently convincing that it led centuries of theorists to neglect treating population as endogenous (Ehrlich and Lui, 1997).

The development of the neo-classical growth models, as best represented by Solow (1956), was the first significant breakthrough since Malthus' theory. It replaced the constraint of land, and thus food supply, with an endowed level of production technology that would make the rate of capital formation match or surpass the rate of population growth in the long run, hence lifting the constraint imposed by the Malthusian trap (Ehrlich and Lui, 1997). Influenced by human capital theory and health economics (Grossman, 1972; Ehrlich and Chuma, 1990), fertility and longevity have more recently been treated as endogenous variables as well. The co-incidence of the second phase of industrialization of less developed economies and the timing of demographic transition has led many researchers to argue that the rising importance of, and the demand for, human capital induced parents to invest more in their children's education, leading to the onset of the demographic transitions (Becker 1981; Galor 2005). Improved technology eased households' budget constraints and provided more resources for them to invest in their children (Galor 2005). While a choice remains between larger families and greater investment per child, at least from an empirical perspective technology improvement tends to cause households to channel their excess resources towards the latter (Galor and Weil, 1999, 2000). Other factors reinforcing demographic transitions include the decline in child labor brought forth by the industrial demand for human capital (Hazan and Berdugo 2002), increased life expectancy, and changes in marriage institutions (Edlund and Lagerlof, 2006; Gould, Moav and Simhon, 2008).

In light of the above human capital argument, Caldwell (1978) assesses the influence of compulsory education on the demand for children and raises the concept of "wealth-flow 
theory," which looks at the economics of children. He argues that, in less developed countries, children are viewed as economic assets in that they provide labor to production and social security to parents; however, as a country increases its need for education, the economic benefits of children diminish because of the cost of compulsory education. Cleland and Rodriguez (1988) compare the effects of a wife's education versus a husband's education on fertility and find that, after adjustment for education of the spouse and related economic variables, the wife's education emerges as the more decisive influence. Most analyses attribute low and delayed fertility to the difficulties women face in combining childbearing with their education and career in contemporary industrialized society (Gasahl, 2006).

Regarding the relationship between demographic transition and economic status, it is argued that population growth is a hump-shaped function of income per capita (Kalemli-Ozcan, 2002; Galor, 2005). At low levels of income and prior to the demographic transition, population growth increases with investment in human capital and the rise of income per capita. This leads to a Malthusian steady-state equilibrium. But when income levels reach some sufficiently high threshold, a demographic transition takes place, causing a decline in population growth and permitting further increases in human capital formation. This then leads to a sustained-growth, steady-state equilibrium. The causal relationships between population and per capita real income are primarily bound over the longer-run horizon rather than the shorter-term (Darrat and Al-Yousif, 1999).

Urbanization's close association with demographic transitions has also received some attention. It has been observed that many countries that have undergone demographic transition have also had remarkable advances in urbanization (Bairoch, 1988; Sato and Yamamoto, 2005). Schultz (1985) uses aggregate county-level data of Sweden for the period 1860 to 1910, and identifies demand-induced changes in the price of women's time as a factor that determines the fertility transition. As urban-industrial settings and values increase employment opportunities for women (Micklin, 1969), their time values increase, leading to fertility reduction. Sato and Yamamoto (2005) investigate the effects of agglomeration economies and congestion diseconomies on demographic transition. By assuming decline in the infant mortality rate, their model can simultaneously replicate the well-known historical patterns such as advances in urbanization, rise in the wage rate, and the inverted U-shaped demographic transition, demonstrating that urbanization plays a pivotal role in the process of economic development accompanied by demographic transition (Sato and Yamamoto, 2005).

Tien (1984) finds that both socio-economic change and population control policy played a fundamental role in China's recent fertility transition, and in places where family planning was the most effective, there have also been profound changes in socio-economic structure. A similar conclusion is drawn by Posten and Gu (1987), who look at 28 subregions of China using data from the country's 1982 census. They find that China's fertility decline should not be viewed as solely due to successful population control policy. Birdsall and Jamison (1983) acknowledge that China's fertility decline was correlated with income increases, even before the one-child policy was implemented. Merli and Herbert (2002) argue that in China the acceptance of 
policy-sanctioned family size follows a development gradient: high acceptance occurs in the most urban, industrialized counties and acceptance is weaker among women living in the poorest counties.

The above literature holds a common view that demographic transition, especially fertility transition, is driven by a set of socio-economic factors, including industrialization, income, urbanization, and educational attainment, especially of women. China's experience also shows that population policy alone may not be sufficient to curtail high fertility, but that economic development appears to be a reliable contraceptive.

\section{CHINA'S ECONOMIC REFORM AND POPULATION CONTROL POLICY}

\subsection{China's Economic Reform and Regional Disparity}

China's economic reform policy has greatly reshaped the economic landscape of the country. The 1978 reforms were framed to favor certain regions that already enjoyed locational advantages. The idea was that they would demonstrate China's strengths and thereby attract foreign capital.

Economic reforms were carried out incrementally, starting in China's coastal areas. Selected seaport cities were targeted first, then major metropoles, and finally the "growth poles" expanded to broader integrated areas, including the whole Yangtze River Delta, the Pearl River Delta, and the greater Beijing-Tianjin metropolitan area. However, Central and West China were excluded until 1999 when the central government officially proposed "the grand development of Western regions." Growing regional disparity between the coastal area and the hinterland triggered much pressure to effect this policy, which was designed to address the lower living standards of the lagging regions. The central government also put programs in place to reinvigorate Northeast China's traditional industrial base and the "Central China Development Plan” in 2003 and 2004, respectively.

The basis of China's economic reform policy lies in the principles laid out by Hirschman (1958), who suggests that "an economy, to lift itself to higher income level, must and will first develop within itself one or several regional centers of economic strength.” The government thus acquiesced in that "interregional inequality of growth is an inevitable concomitant and condition of growth itself" (Hirschman, 1958), and hoped that the subsequent "trickling-down" of economic prosperity from growth centers would generate positive spillovers to the hinterland and smooth out regional income disparities in the long run. However, it can take a long time for wealth to spillover from one region to another. As a result, a dualistic structure is imprinted upon the spatial economy of today's China: a strong center — the coastal area-has formed with the Shanghai-led Yangtze River Delta, the southern Pearl River Delta and the Beijing-Tianjin metropolitan area as its cores. And the periphery-i.e., Central China, West China and the Northeast—lags ever further behind. 
Figure 1 shows China’s 2004 regional gross product per capita (in Chinese Yuan), ${ }^{1,2}$ and Figure 2 shows the ratio of rural residents' income to the national rural average. A declining gradient of economic well-being is readily observed from the Coast through Central China and Northeast China to West China. The spatial disparity of urban residents' income roughly follows the core-periphery pattern as well, although the pattern is not as distinct as that presented in Figures 1 and 2. This finding implies that there may be more income similarities among China's urban areas than there are among rural areas.

The above discussion of China's regional income gap indicates that the spatial equilibrium model, which puts faith in the unhindered operation of the market forces to restore regional equity, can fail to work in developing countries. While the development of interregional infrastructure is designed to facilitate spatial diffusion to connect the periphery more closely to the core, it just as readily makes the core more accessible to the periphery. As a result, polarization between backward regions and the core can accelerate (Richardson, 1978) through a displacement of an array of production factors including labor, capital, and raw materials from the periphery to the core (Friedman 1966).

\section{FIGURE 1. Provincial Gross Product Per Capita, in 2004 Yuan}
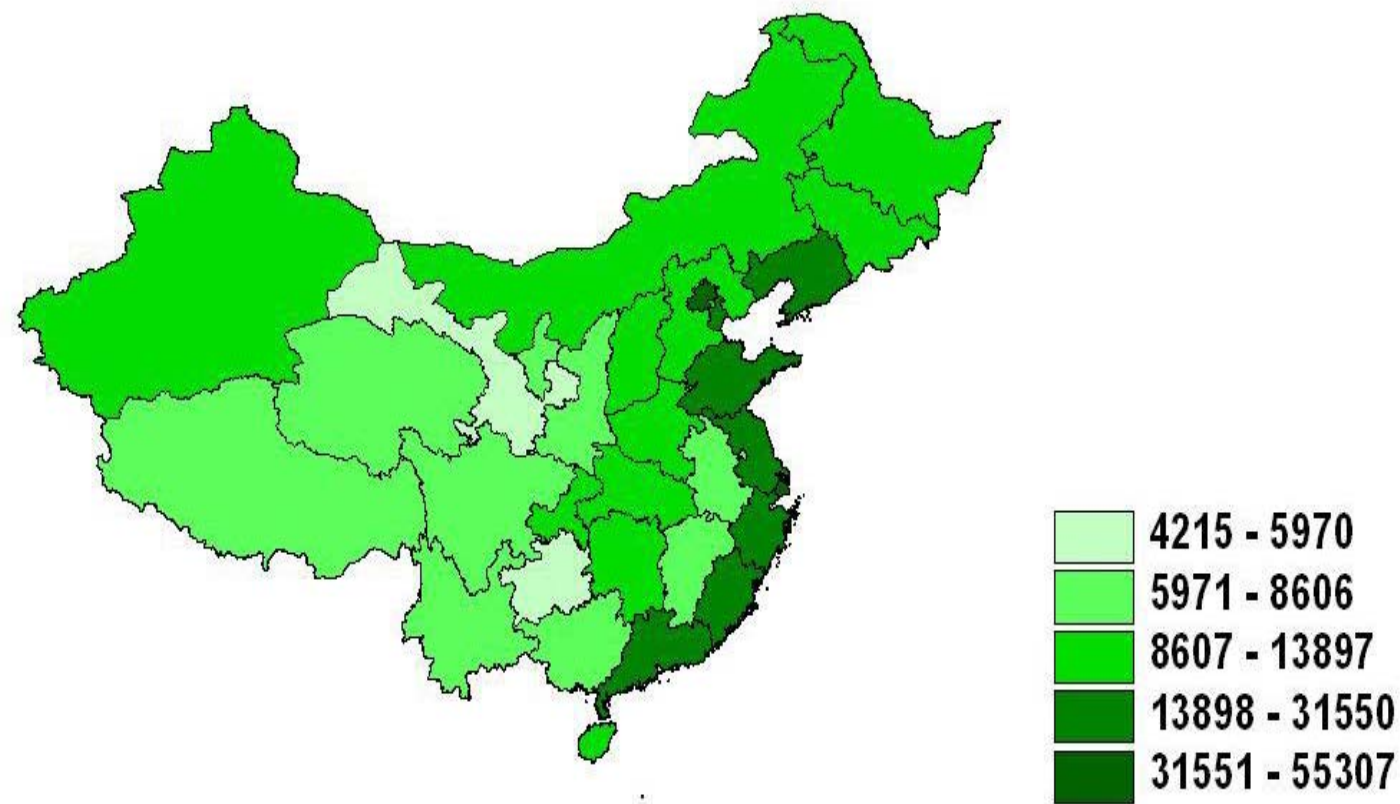

Source: The original data for the map are from China Statistical Yearbook 2005, Available at www.stats.gov.cn (last accessed April 2007).

\footnotetext{
1 This includes 22 provinces, 5 ethnic autonomous regions, and 4 municipalities-Beijing, Shanghai, Tianjin, and Chongqing. Hong Kong, Macao and Taiwan are not included due to data availability issues.

2 At the time of research for this paper, the most recent statistics available were those from the 2005 Statistical Yearbook, which contains data as recent as those for 2004.
} 


\section{FIGURE 2. The Ratio of Rural Residents’ Income to the Rural National Average, 2004}
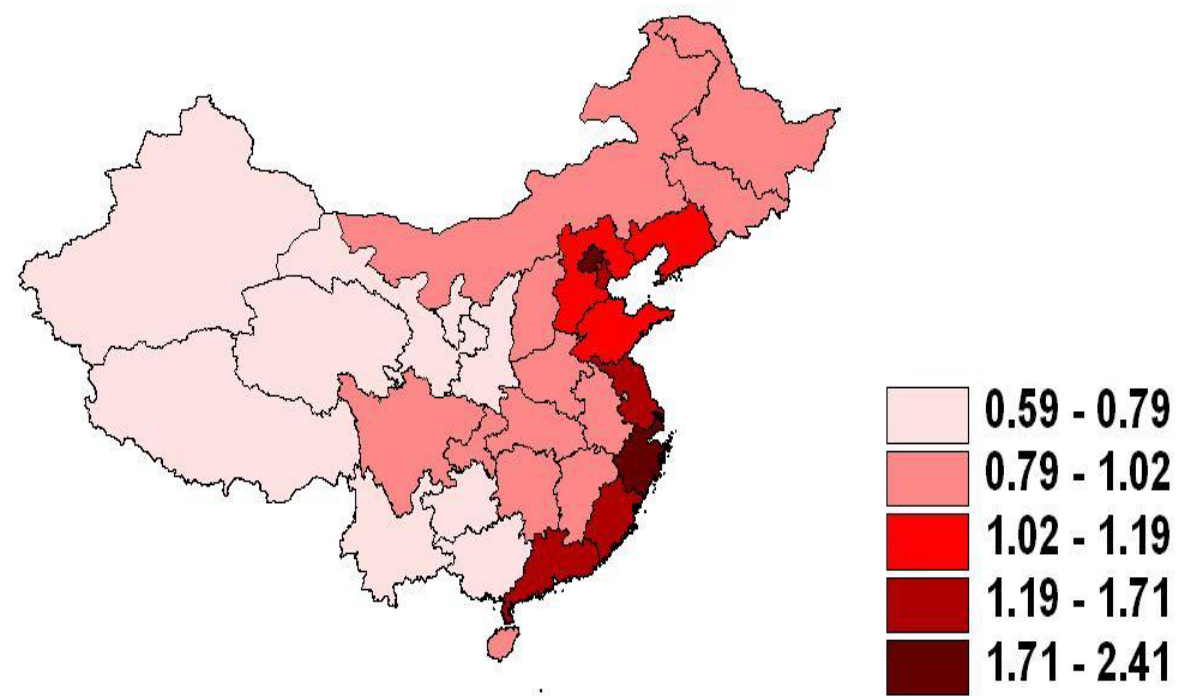

Source: The original data for the map are from China Statistical Yearbook 2005.

\subsection{China's Population Control Policy and Its Consequences}

When the People's Republic of China was founded in 1949, the central government adopted a Marxist view of population growth. The Marxist perspective regards a large population as an asset, viewing revolution and production as solutions to hunger. The total fertility rate (TFR) was about 5.7 from 1949 to 1958 (Coale and Li, 1987). It fell to 3.9 around the time of the Great Leap Forward, but this was undoubtedly due to a three-year nationwide famine from 1958 to1960. In the 1960s the birth rate rose again and the total fertility rate peaked with an annual average of 6.1 from 1962 to 1970. As the size of the population slowly became a national concern, the central government shifted its attitude, favoring anti-natal policies. Fewer children resulted and a larger interval between births was advocated. In 1973, a hierarchy of responsibility was established: it promoted a national birth control campaign (Gasahl, 2006), resulting in a lower total fertility rate-3.4 for the 1970s. Meanwhile, the traditional Confucian concept of the family, which proposed that more sons meant more blessings to the family and considered women to be subservient, came into question.

The one-child policy was officially implemented in 1979. It established a network of family-planning organizations that provided contraceptive services and birth control education. It also offered a variety of social and economic incentives and disincentives from the central government to couples who opted to bear just one child. The incentives included education and medical care benefits for the only child and a favorable housing allocation for the parents; disincentives included a monetary penalty and the cancellation of parents' job promotion opportunities for any unplanned fertility behavior (Li, 2005; Gasahl, 2006). 


\section{FIGURE 3. China's Total Fertility Rate and Population Growth Rate, 1970-2005}

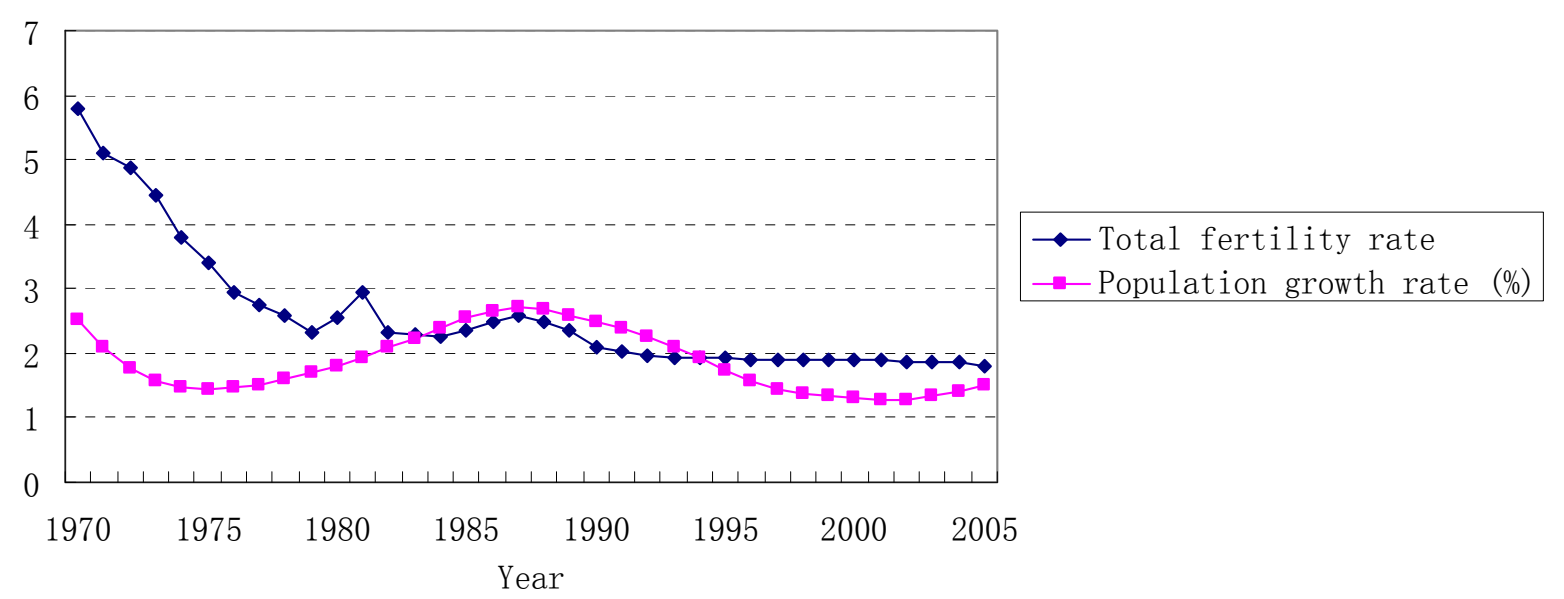

Source: The original data are from OECD Factbook 2008.

China's fertility rate, generally speaking, has been responsive to the one-child policy. According to the U.S. Census Bureau's International Data Base, in 2005 the total fertility rate dropped to 1.7. ${ }^{3}$ Figure 3 shows the trend in China's total fertility rate and population growth rate from 1970 to 2005. Despite the apparent steadiness of the trends, the degree of acceptance and compliance with the one-child policy differed across regions. It particularly created hardship for rural populations who were more entrenched in the traditional pro-natal culture and believed more sons both carried on the family name and would secure more income for the family. The "problem of the missing girl" became serious in rural areas, as abortion enabled families to rid themselves of less desirable female fetuses. As a result of this concern, the central government relaxed the one-child policy to some extent in mid 1980s and permitted some latitude. For instance, rural families were allowed to have a second child if the first was a girl or was born disabled, and ethnic minorities were granted even greater leniency. These exceptions gave rise to uneven enforcement and subsequently different fertility rates between urban and rural areas, and between regions inhabited by the ethnic Han and those mainly inhabited by ethnic minorities. ${ }^{4}$ Nevertheless, in coastal urban areas, people were amenable to family planning even when and where population policies were not in place, and new trends emerged as some career women voluntarily chose not to have children.

\footnotetext{
3 The total fertility rate is defined as births per woman. Data are available at http://www.census.gov/cgi-bin/ipc/idbsum.pl?cty=CH (last accessed April 2007).

${ }^{4}$ Han is the largest ethnic group in China, which accounts for about 92 percent of the total population. The other 55 minority ethnic groups account for 8 percent of the total population, and they are concentrated in the five ethnic autonomous regions-Tibet, Xinjiang, Ningxia, Inner Mongolia, and Guangxi.
} 


\section{CHINA'S REGIONAL DISPARITY IN DEMOGRAPHIC TRANSITION: FROM A SOCIO-ECONOMIC PERSPECTIVE}

\subsection{Hypotheses, Data, and Method}

This paper explores the spatial dynamics of China's demographic transition, specifically transitions in fertility, age structure, migration, and household size. It empirically examines the relationship among these demographic transitions and various socio-economic factors. Cross-sectional data by province were collected from the 2005 China Statistical Yearbook, which records the data through 2004-the most recent data available when this research was undertaken. ${ }^{5}$ As China formed a salient dualistic economic structure, with the coastal growth poles and a lagging hinterland, this paper is focused on the relationship between a region's economic conditions and its corresponding status in demographic transition.

Hypothesis 1. China's spatial pattern of demographic transition roughly follows the economic development gradient across its regions.

Proxy measures (largely extracted using a one-percent sample of the population) for each type of demographic transition are as follows:

(1) Fertility transition-measured by the percentage of only child among the population under 30. ${ }^{6}$ This indicator captures China's unique transition profile under the one-child policy

(2) Age transition - measured by the youth dependency ratio, the elderly dependency ratio, and average life expectancy across regions.

(3) Household transition-measured by the household size, using three people per household as the cut-off point. This threshold is applied because under the population control policy, a typical Chinese family should only include parents and one child. Hence, three is the normal size for a nuclear family.

(4) Migration transition-measured by the percentage of population whose "hukou" is not from the local area, and by net migration calculated as a residual from the usual demographic equation.

Since "hukou" is a term particular to China, it deserves some special mention here. Hukou status is used as a proxy measure for in-migration here because it is the only official data available that can roughly depict the pattern of provincial in-migration (largely from hinterland to growth centers). Hukou is a registration system based on the place of birth and is categorized into "urban hukou” and "rural hukou." The registration system is designed to discourage

\footnotetext{
${ }^{5}$ The China Statistical Yearbook is by far the most official and comprehensive data source, and its data quality has been improved in recent years. However, there still remain many problems with the Chinese data. For instance, due to the exceptionally large population, many data, except for those from the census, are 1\%o sampling data, which increases the margin of error. Some time-series data lack consistency due to changing variable definitions and measuring criteria over the years. Lack of detailed data in economic and demographic fields also poses challenges for in-depth studies.

${ }^{6}$ Only-child data are from year 2005 and are generated from a 1.3 percent sample of observations. Thus they should be more representative and accurate.
} 
mobility between villages and cities. Thus, if someone without an "urban hukou” opts to reside in a city, he or she still cannot enjoy many welfare benefits granted to those with an "urban hukou.” But this dichotomous system does not stop people in the periphery from migrating into leading urban cores for job opportunities and better life quality. This stream of in-migrants officially is a set of temporary urban residents, and accounts for a sizeable chunk of many cities' inhabitants. The reality is that the migrant workers tend to remain in cities, raising families there. Their children are subsequently granted an urban hukou.

The socio-economic factors as explanatory variables include:

(1) Regional economic well-being measured by provincial gross product per capita (in Chinese Yuan), urban residents' income and rural residents’ income; ${ }^{7}$

(2) Regional urbanization level measured by the percentage of urban population, and population density;

(3) Regional industrialization level measured by location quotients of the primary industry, ${ }^{8}$ secondary industry, ${ }^{9}$ and tertiary industry; ${ }^{10}$

(4) Regional education levels measured by the percentage of population 6 years and above that have completed nine years' compulsory education (i.e., primary and junior-high schooling); percentage that hold a college degree, for men and women separately; and adult illiteracy rate (percentage of population 15 years and above who are illiterate or quasi-illiterate), for men and women separately.

According to the literature, wealthier, more urbanized and industrialized regions, and regions with a larger share of highly educated people are expected to exhibit a greater degree of demographic transition. Major hypotheses to be tested include:

\section{Fertility transition:}

Hypothesis 2. A region's percentage of children in single-child families is positively related to its percentage of urban population, urban and rural residents' income, the location quotients of secondary and tertiary industries, and the percentage of population with college education, but negatively related to the percentage of illiterate population.

\section{Age transition:}

Hypothesis 3a. A region's population life expectancy is positively related to its urban and rural residents' income, and its share of population that is urban.

\footnotetext{
7 There are no overall residents' income data available. This is due to the large gap between urban and rural residents' economic well-being, and differentiation between urban and rural residents' income must be made or the aggregate data will be distorted.

8 Primary industry mainly refers to agriculture.

9 Secondary industry includes manufacturing and construction.

10 Tertiary industry includes transportation, communications, services, wholesale, retail, trade, finance, insurance, real estate, and other related sectors.
} 
Hypothesis $3 \boldsymbol{b}$. A region's youth dependency ratio is negatively related to its percentage of urban population, and urban and rural residents' income. This runs opposite to the elderly dependency ratio.

\section{Migration transition:}

Hypothesis 4. A region's percentage of population without local hukou is positively related to its urban residents' income, ${ }^{11}$ percentage of urban population, and the location quotients of secondary and tertiary industries.

\section{Household transition:}

Hypothesis 5. A region's percentage of households with more than three people is negatively related to its urban and rural residents' income, and the location quotients of secondary and tertiary industries.

This paper relies on maps to observe the regional disparity pattern of the demographic behavior. Regression analysis is used to explore the possible strength of any links between demographic variables and social-economic characteristics. Data for Hong Kong, Macao, and Taiwan are not available and are not included in the map presentation.

\subsection{Fertility Transition}

The one-child policy is clearly a major contributor to China's fertility transition. The degree to which China's people comply with it varies quite a bit across regions, however. Figure 4 shows the provincial percentage of population under 30 years old who were the only child born to their parents. The spatial disparity of this variable roughly follows the gradient of regional economic well-being. The coastal areas have a relatively high percentage of only child, while Central China's share is somewhat lower, and West China's is least. A global Moran's I of 0.41 under a first-order rook contiguity weights matrix indicates a moderate spatial clustering pattern.

Some exceptions stand out in the map. Northeast China, i.e., Heilongjiang Province, Jilin Province, and Liaoning Province, is economically a peripheral area, yet it is one of the regions that enforces the one-child policy most strictly with an average of 49.5 percent of the under 30 population identifying themselves as the only child in their families. This high level of compliance can be explained by Northeast China's high urbanization level. While 36 percent of the nation's population was located in urban areas in 2000, 51 percent of Northeast China's population was urban-higher than several coastal provinces that are now more economically developed. Before the 1980s, Northeast China was the country's heavy industry base and maintained a high concentration of state-owned enterprises in machinery manufacture, steel production, and petroleum refining. This relatively high industrialization led to correspondingly high urbanization. As the country later shifted its focus from heavy industry and state-ownership toward a market economy, the region's economy lost its vitality, suffering some decline during the transition. Yet the tradition of rigid family planning has taken root in the area. With regard to

\footnotetext{
${ }^{11}$ Urban residents' income is expected to matter more than rural residents' income in migration transition because urban areas are usually the destination for in-migration.
} 
the dark area in China's southwest in Figure 4, it was in Sichuan Province that the one-child policy was first tested before it became a national policy. Thus, a legacy of strict compliance appears to remain there. The low percentage of the population that is only-child in Guangdong Province in southern-most China is not in line with either its economic status or urbanization level. Clearly the causes of this anomaly need to be explored further and may be related in part to the region's cultural differences.

\section{FIGURE 4. Percentage of Population Born as Only Child (2005) and Global Moran's $I^{12}$}
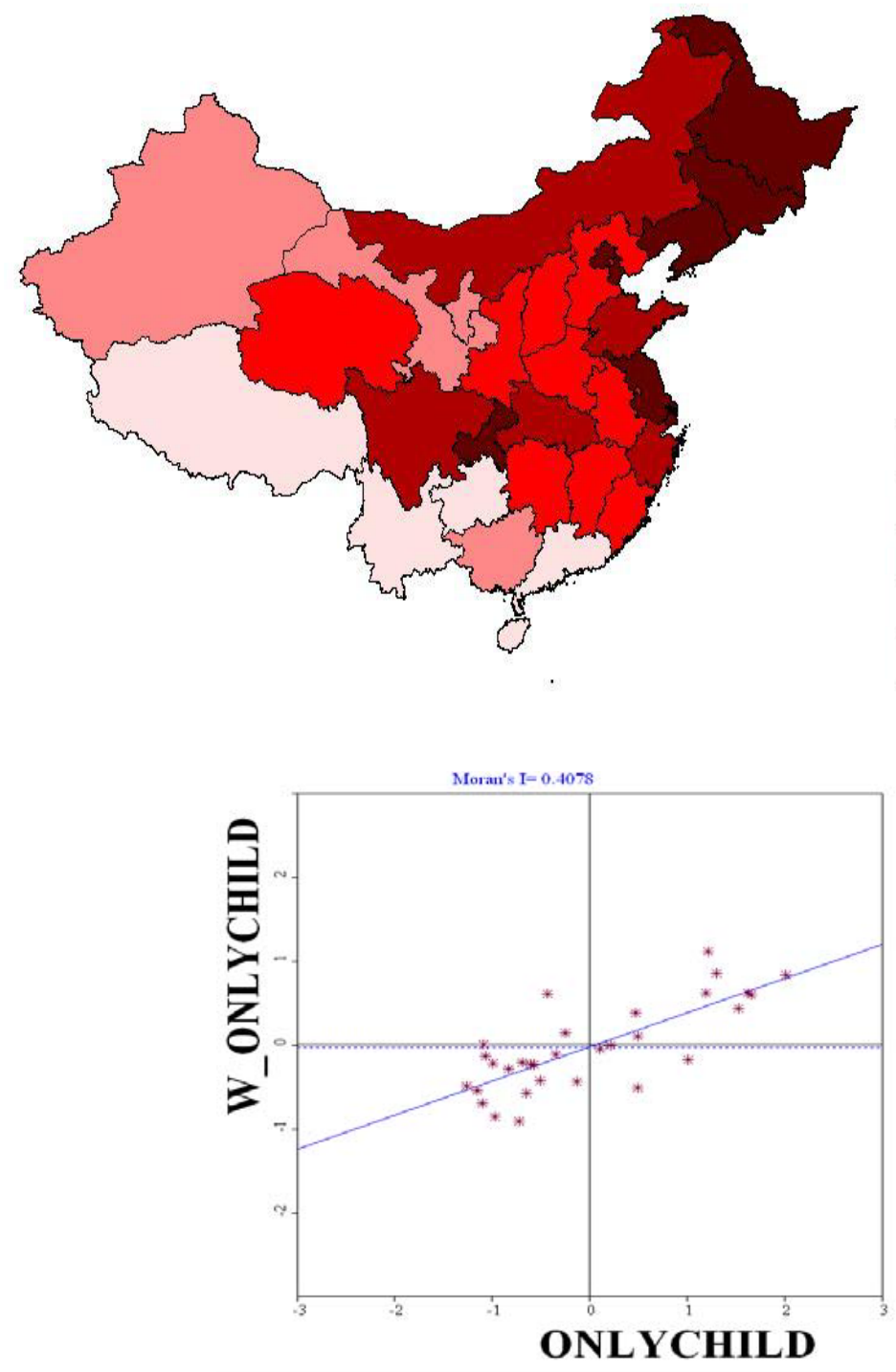

Source: The original data for the map are from China Statistical Yearbook 2005.

\footnotetext{
${ }^{12}$ Moran's I is calculated using rook first-order contiguity weights matrix.
} 
The overall pattern represented in the map suggests that urbanization correlates strongly with the degree of compliance with the one-child policy. This makes sense, since the correlation could at least be partially caused by the relaxation of the policy in rural areas and the prevailing mindset in urban areas that family planning is needed. This is reinforced by a social security system that is more developed in urban areas than rural areas. As a result it is likely that rural parents continue to cling to the tradition of having more than one child to assure financial security in their old age.

To further explore the relationship between the percentage of population born as only child and other socio-economic factors, regression analysis is used. Due to a potential multicolliniearity problem, the influence of each set of socio-economic factors must be estimated separately. Spatial lag and spatial error models treat any spatial autocorrelation problems.

Income, urbanization, and fertility. Table 1 shows that a 1,000 Yuan increase in a region's rural residents' income is significantly associated with a 9.1 percentage point increase in the only-child population. Also, each 10 percentage point increase in a province's urban area resident population is associated statistically with a 3.7 percentage point increase in the only-child population. Although using a spatial lag or spatial error model does not remove spatial dependence problems, it does improve the model's goodness of fit. Yet surprisingly, after controlling for both rural residents' income and the percentage of population that is urban, urban residents' income is negatively associated with the percentage of only child, though the coefficient is small. This could result because being in an urban area is enough to explain compliance with the one-child policy and income levels in urban areas therefore do not have much influence. The acceptance of the policy in rural areas, where a second child may be desired to provide more economic security in parents' sunset years, is more sensitive to the personal income level of the particular area with wealthier rural parents needing less security from a second child.

Education and fertility. Table 1 also shows that each one percentage point increase in the population with a college degree is significantly associated with a 0.98 percentage point increase in the only-child population. This effect is stronger for females than males, as each one percentage point increase of women with college education is significantly associated with a 1.03 percentage point increase in the only-child population. As Handwerker (1986, 1989, 1991) argues, women begin to reduce fertility when they can attain status, prestige, and wealth by means other than having children. In his view, fertility decline results from "changes in opportunity structure that increasingly reward educationally acquired skills and perspectives" (Handwerker, 1986, p. 42) and such opportunities are more available to educated women. The above results agree with his argument, although differences are too slight to reach a definite conclusion. Adult illiteracy rate is less relevant than college education, but females' illiteracy rate is still more significant than that of males. However, when the percentage of population who finish the 9-year compulsory education is included as a regressor, its coefficient is not significant. This is partly because compulsory education is provided at a low cost in China and may not be 
TABLE 1. Percentage of Population Born as Only Child and Socio-Economic Factors

\begin{tabular}{|c|c|c|c|c|c|c|c|c|c|c|c|c|}
\hline & \multicolumn{2}{|c|}{ (1) Income } & \multicolumn{4}{|c|}{ (2) Industrialization } & \multicolumn{6}{|c|}{ (3) Education } \\
\hline & Coef. & Sig. & (2a) Coef. & Sig. & (2b) Coef. & Sig. & (3a) Coef. & Sig. & (3b) Coef. & Sig. & (3c) Coef. & Sig. \\
\hline W_only child & & & & & & & 0.6727 & $* * *$ & 0.6613 & $* * *$ & 0.6844 & $* * *$ \\
\hline Lambda & 0.7728 & $* * *$ & 0.6649 & $* * *$ & 0.6605 & $* * *$ & & & & & & \\
\hline Urban income & -0.0032 & $* *$ & & & & & & & & & & \\
\hline Rural income & 0.0091 & $* *$ & & & & & & & & & & \\
\hline Urban population & 0.3675 & $* *$ & & & & & & & & & & \\
\hline LQ primary industry & & & & & -29.7771 & $* * *$ & & & & & & \\
\hline LQ secondary industry & & & 14.7018 & $* * *$ & & & & & & & & \\
\hline LQ tertiary industry & & & 19.1102 & $* * *$ & & & & & & & & \\
\hline College & & & & & & & 0.9780 & $* * *$ & & & & \\
\hline College-Female & & & & & & & & & 1.0324 & $* * *$ & & \\
\hline College-Male & & & & & & & & & & & 0.9175 & $* * *$ \\
\hline Illiteracy rate & & & & & & & -0.3457 & $*$ & & & & \\
\hline Illiteracy-Female & & & & & & & & & -0.2821 & $*$ & & \\
\hline Illiteracy-Male & & & & & & & & & & & -0.4415 & \\
\hline Constant & 10.3087 & & -5.2389 & & 58.3374 & $* * *$ & 8.4758 & & 9.9809 & $*$ & 6.7532 & \\
\hline$R^{2}$ & 0.742 & & 0.675 & & 0.672 & & 0.659 & & 0.657 & & 0.659 & \\
\hline Prob. spatial dependence & 0.089 & & 0.004 & & 0.004 & & 0.000 & & 0.000 & & 0.000 & \\
\hline
\end{tabular}

Notes:. Dependent variable: percentage of population (under 30 years old) born as only child. *** denotes statistical significance at 0.01 ; $* *$ denotes statistical significance at $0.05 ; *$ denotes statistical significance at 0.1 . The models use $1^{\text {st }}$ order rook contiguity weights matrix. Model (3b) estimates the influence of females' education level; model (3c) estimates the influence of males' education level. The last row reports probability of spatial dependence after running the spatial lag or spatial error model. 
able to substantially reduce a couple's desired birth target in such a way as Caldwell's economics of children has suggested.

Industrialization and fertility. The relationship between the level of industrialization and the percentage of only-child population is also examined. Location quotients of primary and secondary industries are mapped in Figures 5 and 6. Provinces in West China and most of China have employment location quotients in agriculture that are greater than one. Coastal provinces are the most industrialized. Regression analysis (see Table 1) shows that employment location quotients of primary industry are negatively associated with the percentage of only-child population, while each 0.1 increase in the location quotients of secondary and tertiary industries is, significantly associated with 1.5 and 1.9 percentage point increases in the only-child population. This is easily explained since, in a developing country like China where agriculture is still not sufficiently modernized, peasants tend to hold the view that more children will provide more labor, thus setting higher birth targets.

This section looks at the degree of compliance with the one-child policy across regions, and finds that urbanization level, rural residents' income, college education, and the level of industrialization all play an important role in explaining China's regional differences in fertility transition. What is noticeable is that the wealthiest metropoles in China now have birth rates that are comparable to those in developed countries. In 2004, crude birth rates in Beijing and Shanghai were 6.1 and 6.0 per 1,000 population, respectively, and with a natural increase rate of 0.70 and zero. Clearly, then, migration is the biggest contributor to population growth in these cities.

\section{FIGURE 5. Location Quotient of Primary Industry, 2004}
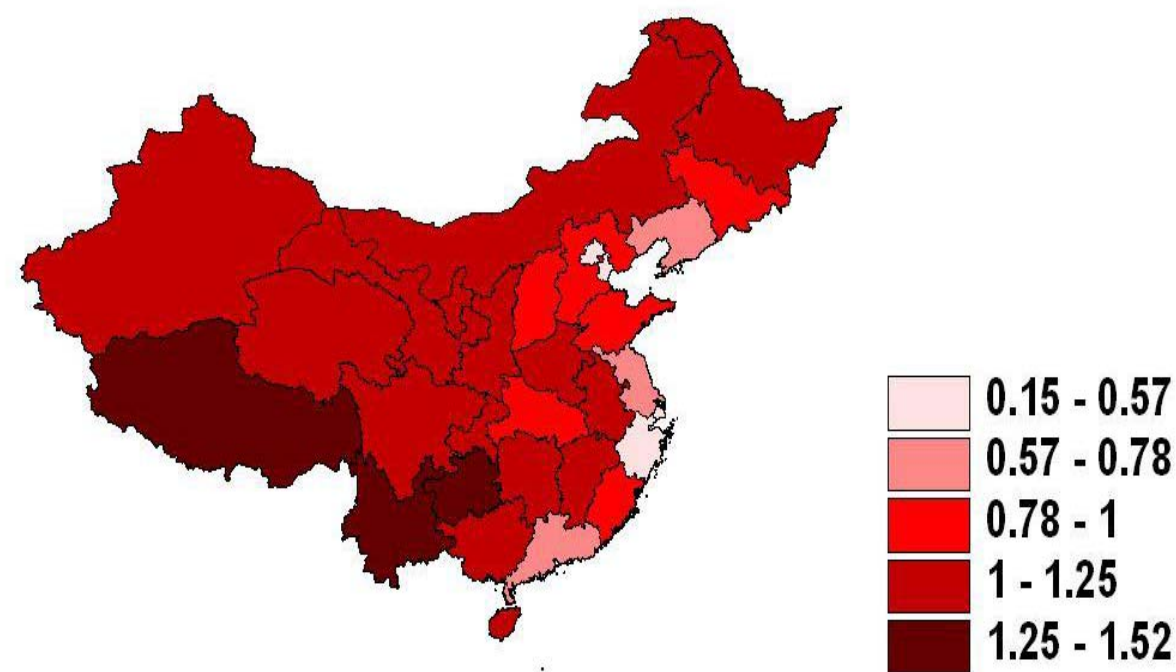

Source: The original data for the map are from China Statistical Yearbook 2005.

Southern Regional Science Association 2010. 


\section{FIGURE 6. Location Quotient of Secondary Industry, 2004}
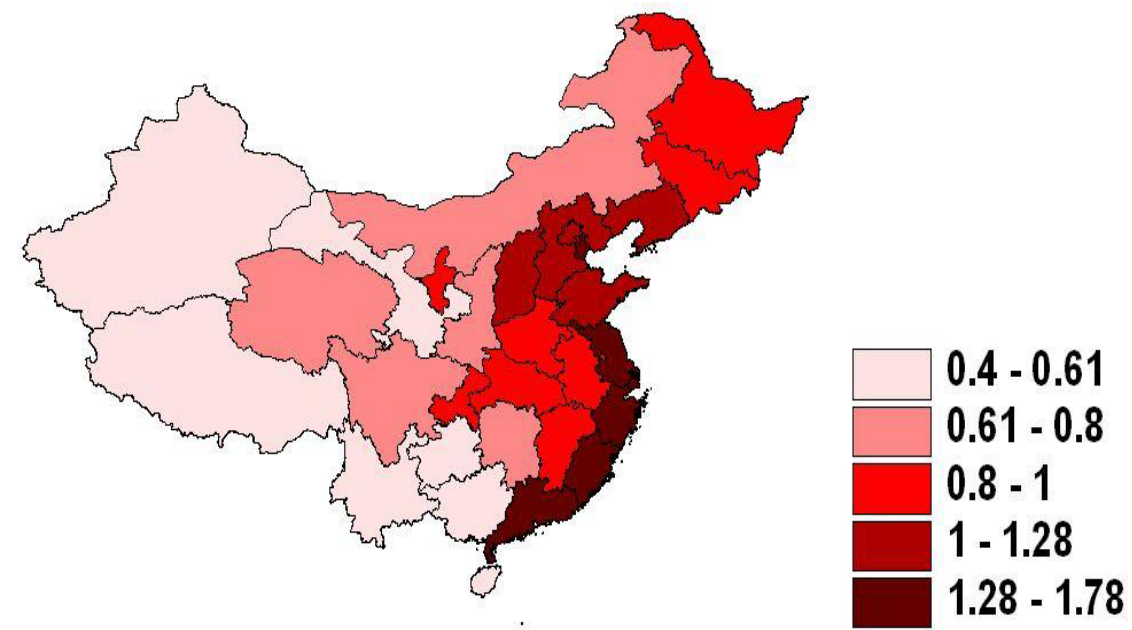

Source: The original data for the map are from China Statistical Yearbook 2005.

\subsection{Age Transition}

China’s life expectancy substantially increased from 1990 to 2000. In 1990, average life expectancy was 68.8 years, with female life expectancy of 70.5 years and male life expectancy of 66.8 years. By 2000, the national average reached 71.4 years, with female life expectancy of 73.3 years and male life expectancy of 69.6 years. While average life expectancy in China has climbed over time, its spatial distribution remains uneven. Figure 7 shows that while Shanghai and Beijing lead with life expectancies of 78.1 years and 76.1 years (including both sexes), respectively, and eastern coastal provinces_-Shandong, Jiangsu, and Zhejiang-enjoy about 3.0 years more than the national average, the majority of Central China varies about the national average and provinces in West China fall below the national average. Life expectancy, frequently used as a proxy measure for standard of living and human welfare in the development literature, has roughly followed the gradient of economic growth, although Northeast China has life expectancies that outpace its relative economic status. A global Moran's I of 0.54 under first-order rook contiguity weights matrix indicates relatively strong spatial clustering.

Regression analysis (see Table 2) finds that each 1,000 Yuan increase in rural residents' income is significantly associated with 2.8 years increase in the average life expectancy of a province's inhabitants. Yet after controlling for rural residents' income and percentage of urban population, urban residents' income again is negatively related to this life expectancy figure, although its coefficient is very small. One possible reason could be that income of residents across urban areas are more similar than are incomes of residents across rural areas. In addition, however, medical systems in urban areas are generally of higher quality while they still vary considerably across richer and poorer rural areas. If so, life expectancy is likely to be more sensitive to rural economic well-being. Recall, this "negative effect” of urban residents' income 
FIGURE 7. Provincial Life Expectancy, 2000
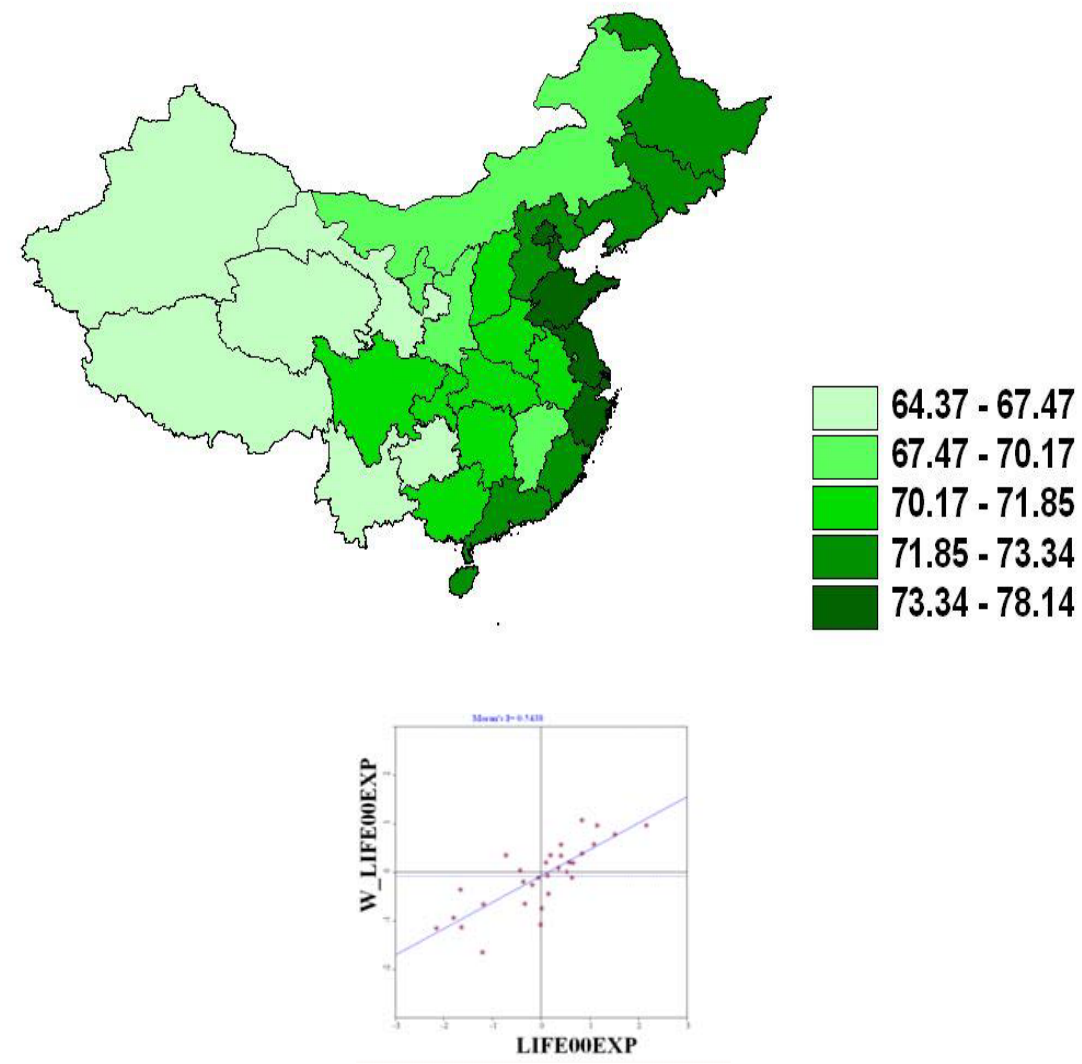

Source: The original data for the map are from the $5^{\text {th }}$ national census.

TABLE 2. Income, Urbanization, and Age Transition

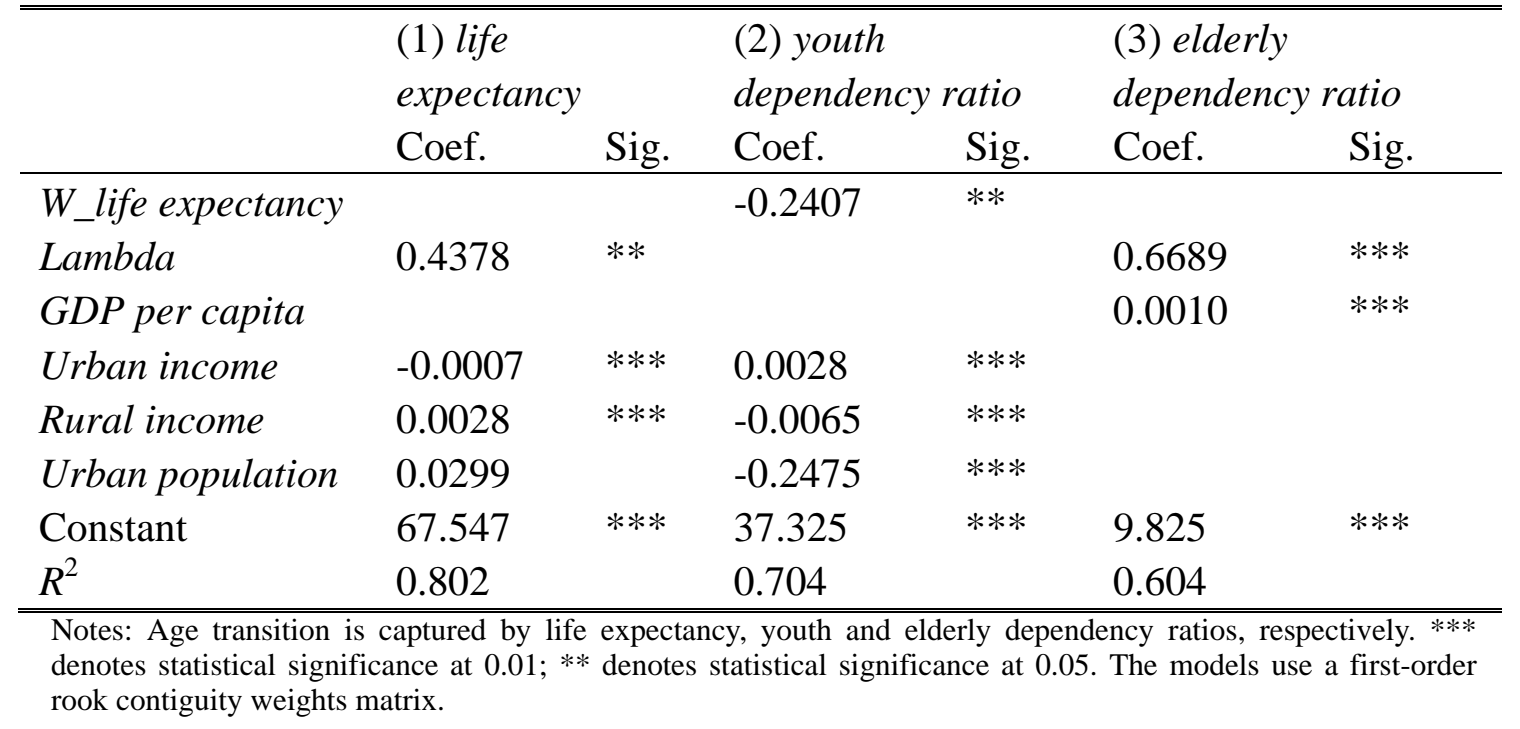

Southern Regional Science Association 2010. 
was observed in the analysis of fertility transition, where it was also surmised that rural areas' living standards were a stronger determinant in China while urban areas have different dynamics that need to be further studied.

The spatial disparity of the dependency ratio is also explored. The youth dependency and elderly dependency ratios are calculated separately in order to better understand the trend in each region's age structure. It is evident from Figures 8 and 9 that the spatial gradient of the youth dependency ratio is practically opposite that of the elderly dependency ratio. While the coastal provinces have lower youth dependency ratios and higher elderly dependency ratios, Central China and West China have higher youth dependency ratios and lower elderly dependency ratios. Higher youth dependency ratios in economically lagging provinces are fairly readily explained by their higher birth rates, and higher elderly dependency ratios in coastal provinces are explained by their higher average life expectancies. Exceptions include Guangdong Province, which though a coastal province and one of the wealthiest regions of China, has one of the highest youth dependency ratios, and Northeast China, which though economically peripheral of late, has a relatively low youth dependency ratio of 18.1 percent-just higher than the three metropoles of Beijing (12.6 percent), Shanghai (11.6 percent) and Tianjin (17.2 percent), and lower than any other province.

Regression analysis (see Table 2) shows that each 1,000 Yuan increase in rural residents' income is significantly associated with a 6.5 percentage point decrease in the youth dependency ratio, and each 10 percentage point increase of the urban population is significantly associated with a 2.5 percentage point decrease in the youth dependency ratio. However, urban residents' income again has an opposite effect from that of rural residents' income, after controlling for the rural income level and percentage of urban population. The results suggest that rural residents' income and urbanization reduce the youth dependency ratio in China.

FIGURE 8. Youth Dependency Ratio, 2004

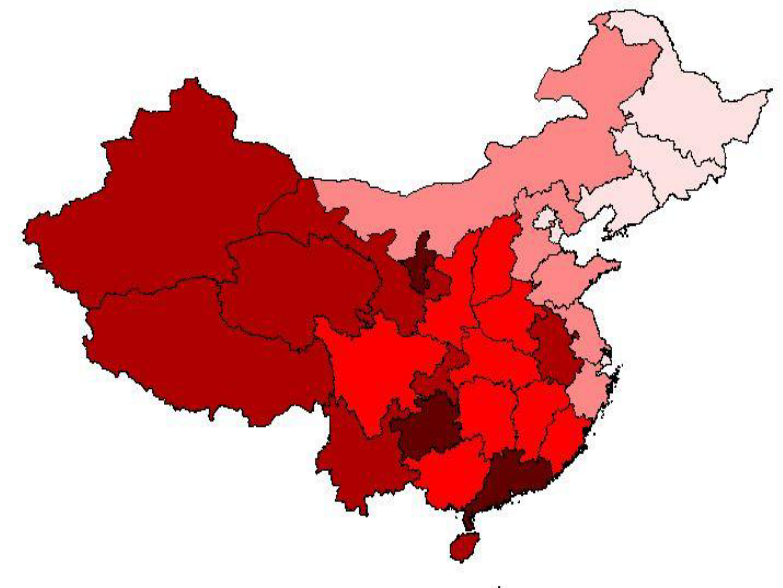

$11.6 \cdot 18.48$

$18.48-23.4$

$23.4-30.67$

$30.67-36.03$

$36.03-38.11$

Source: The original data for the map are from China Statistical Yearbook 2005.

Southern Regional Science Association 2010. 
FIGURE 9. Elderly Dependency Ratio, 2004
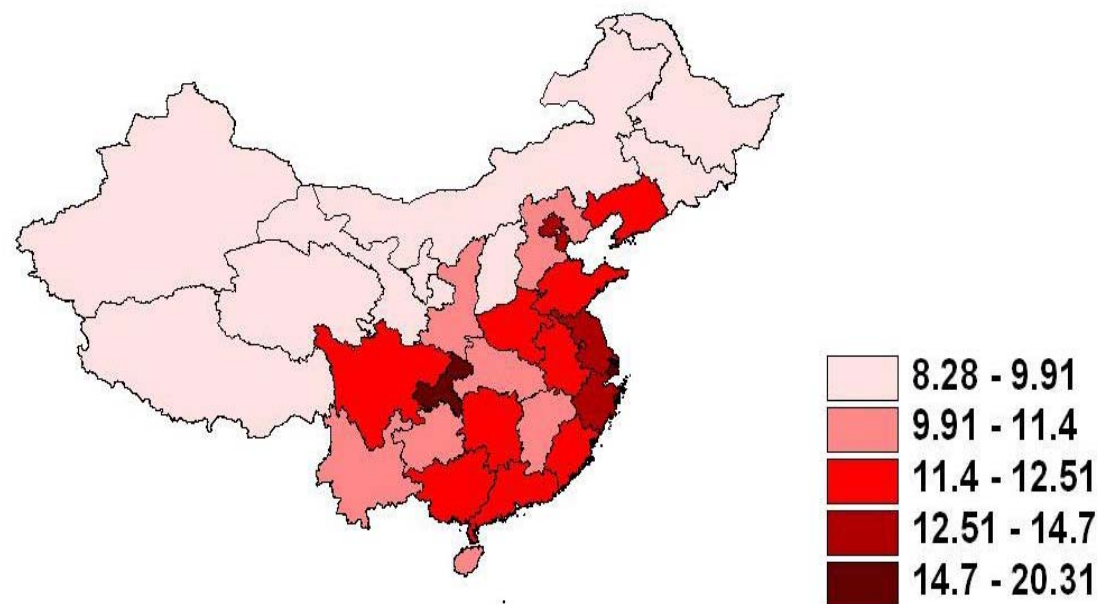

Source: The original data for the map are from China Statistical Yearbook 2005.

\subsection{Migration Transition}

Migration is difficult to measure. Even in the best of data circumstances, the definition of migration is fuzzy (e.g., is suburbanization migration?) and such ambiguity leads to data gathering problems. In China, as is the case in many developing countries, this is further complicated by a general lack of data on the topic. This paper uses the percentage of population without a local hukou ${ }^{13}$ as a proxy measure for in-migration of semi-skilled labor. The pattern of out-migration is not directly explored.

As Section 3.1 has analyzed, the regional income gap expanded after economic reform policy was implemented. During the last two decades a large number of rural peasants have migrated to coastal urban areas for jobs, many of which require physical labor or some low-paying service work (as opposed to the knowledge-intensive creative service jobs) such as in cleaning and tailoring occupations. They do so to secure both better wages and a better quality of life. This phenomenon is widespread in developing countries that adopt a "growth pole" approach to achieve economic transition. It is generally held that wage rates should converge across regions over the long run, since the outflow of labor from the periphery is supposed to raise wages of remaining workers there while an inflow of workers from the periphery is supposed to depress wages at the core (Friedman, 1966). In the short term, however, urban wage rates tend to be higher in the core and inevitably create a dominant periphery-to-core migration trend characterized by the movement of semi-skilled rural labor from Central and West

\footnotetext{
${ }^{13}$ Section 4.1 briefly explains the hukou system in China.
}

Southern Regional Science Association 2010. 
FIGURE 10. Provincial Population Density, 2000
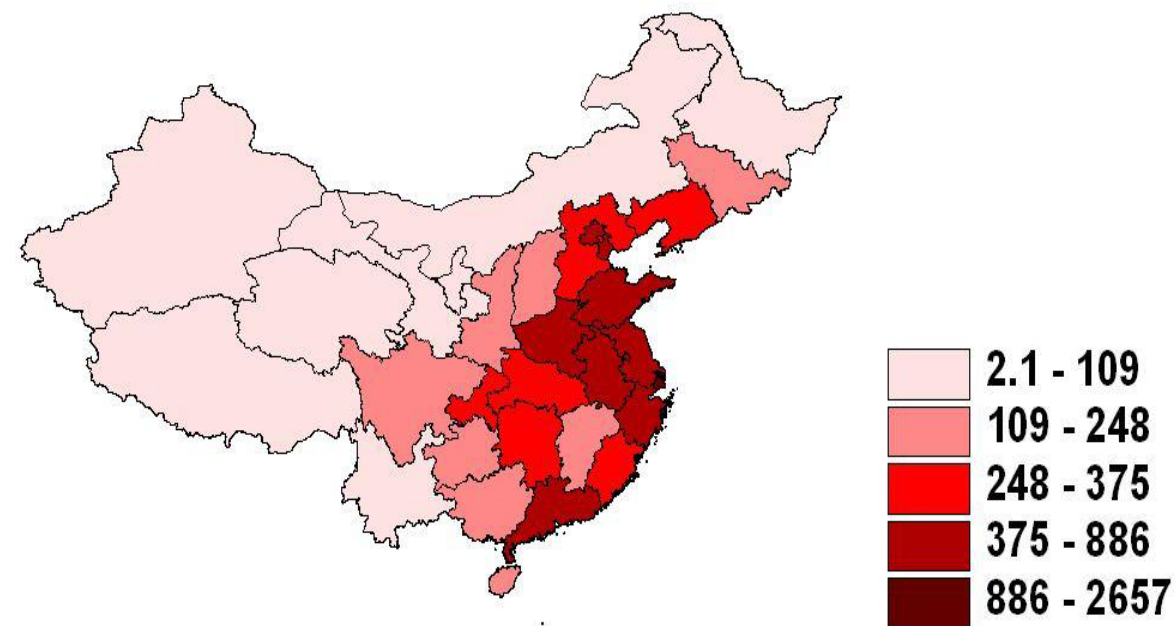

Source: The original data for the map are from the $5^{\text {th }}$ national census.

FIGURE 11. Percentage of Population without Local Hukou, 2004
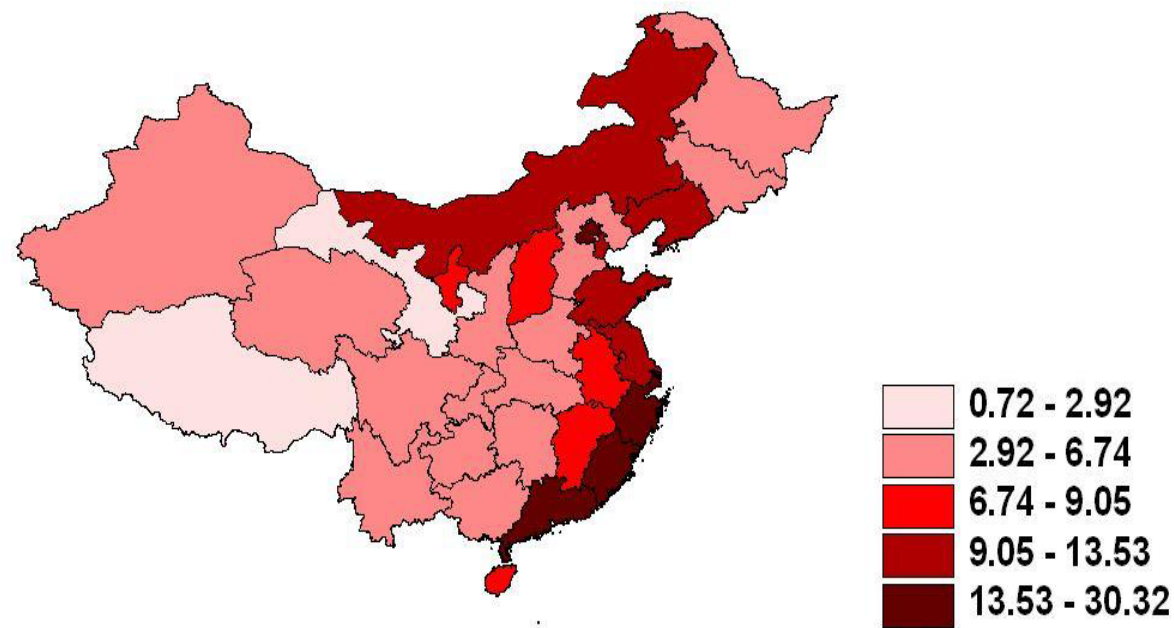

Source: The original data for the map are from China Statistical Yearbook 2005.

Southern Regional Science Association 2010. 
TABLE 3. Migration Transition and Socio-economic Factors (for Semi-skilled Labor)

\begin{tabular}{|c|c|c|c|c|c|c|c|c|}
\hline & \multicolumn{2}{|c|}{ (1) Income } & \multicolumn{4}{|c|}{ (2) Industry mix } & \multicolumn{2}{|c|}{ (3) All } \\
\hline & Coef. & Sig. & (2a) Coef. & Sig. & (2b) Coef. & Sig. & Coef. & Sig. \\
\hline Urban income & 0.0018 & $* * *$ & & & & & 0.0010 & $* *$ \\
\hline LQ primary industry & & & & & -14.9461 & $* * *$ & -8.1035 & $* *$ \\
\hline LQ secondary industry & & & 5.5272 & $* * *$ & & & & \\
\hline LQ tertiary industry & & & 12.1152 & $* * *$ & & & & \\
\hline Constant & -7.7357 & $* * *$ & -9.0452 & $* * *$ & 23.7731 & $* * *$ & 7.6423 & \\
\hline Adjusted $R^{2}$ & 0.609 & & 0.604 & & 0.605 & & 0.660 & \\
\hline
\end{tabular}

China to coastal urban areas. A nonlocal hukou captures this kind of migration, as migrant workers usually settle down in urban areas without a local hukou.

As Figure 10 shows, the East is the most crowded region in the country. The population densities of Beijing, Tianjin, and Shanghai are 823, 886 and 2,657 people per square kilometer, respectively. However, the East also has the highest percentage of population without a local hukou (see Figure 11). This implies that these provinces are experiencing the most intensive in-migration. Liaoning has a high share of population without a local hukou, but it is the most developed among the three provinces in Northeast China and enjoys a location nearest to the eastern coastal provinces. A more conspicuous exception is Inner Mongolia, which has a percentage of population without a local hukou that is comparable to some of the coastal provinces. Yet, Inner Mongolia is generally considered an economically lagging region.

Further regression analysis suggests that higher-than-average urban residents' income may well be a "pull" factor for migrants, while a higher-than-average location quotient of primary industry may be a "push” factor (see Table 3). In provinces with higher urban residents' income and higher location quotients for secondary and tertiary industries, the share of population without a local hukou is relatively high. Urban residents' income is more highly correlated than rural residents' income with the extent of migration. This is likely because migrants tend to select metropoles with higher pay rates and ample job opportunities as their destinations. Most migrant workers seek job opportunities in secondary and tertiary industries rather than in the agriculture industry, in which they have a history of employment; hence, they also prefer as destinations provinces with a more modern industry mix.

But there is a problem with using the hukou concept to measure in-migration, in that it fails to capture the in-migration of knowledge workers. In the metropolitan areas along China's coast, talent is respected and salaries for jobs requiring talent roughly reflect workers' productivities as well as the scarcity of the particular human capital being demanded. In the hinterland, especially Central China and West China, skilled labor is poorly remunerated, either because its importance in the knowledge economy has not been fully realized by the regions' populace or because it carries some non-pecuniary, so-called "spiritual," rewards. With some 
degree of social mobility, this wage gap inevitably leads to the out-migration of the hinterland's best talents, who end up flooding into the coastal urban areas seeking better returns on their human capital, as well as urban cultural amenities and a more dignified way of life for themselves and the next generation. The main way by which these people move into coastal metropolitan areas is by obtaining advanced education. China's education policy stipulates that rural students can be conferred with an urban "hukou" if they get a bachelor's degree or higher from an accredited university and find a job in an urban area. Hence, the migration of these talented people is not counted in the percentage of population without local hukou. Of late, when students who were born in lagging regions move east for a college education, they usually opt to stay there after graduation to pursue a superior career path. The displacement of the hinterland's college graduates has seriously divested those regions of their best talent (via the well known process of "brain drain"), which in turn aggravates regional divergence.

However, the magnitude of in-migration by level of education cannot be measured using data currently available in China. But overall net migration can be derived as a residual of provincial net natural increases and year-end total population figures. Figure 12 presents the annual net migration as a share of provincial total population.

\section{FIGURE 12. Annual Net Migration as a Percentage of Provincial Total Population, 2004}
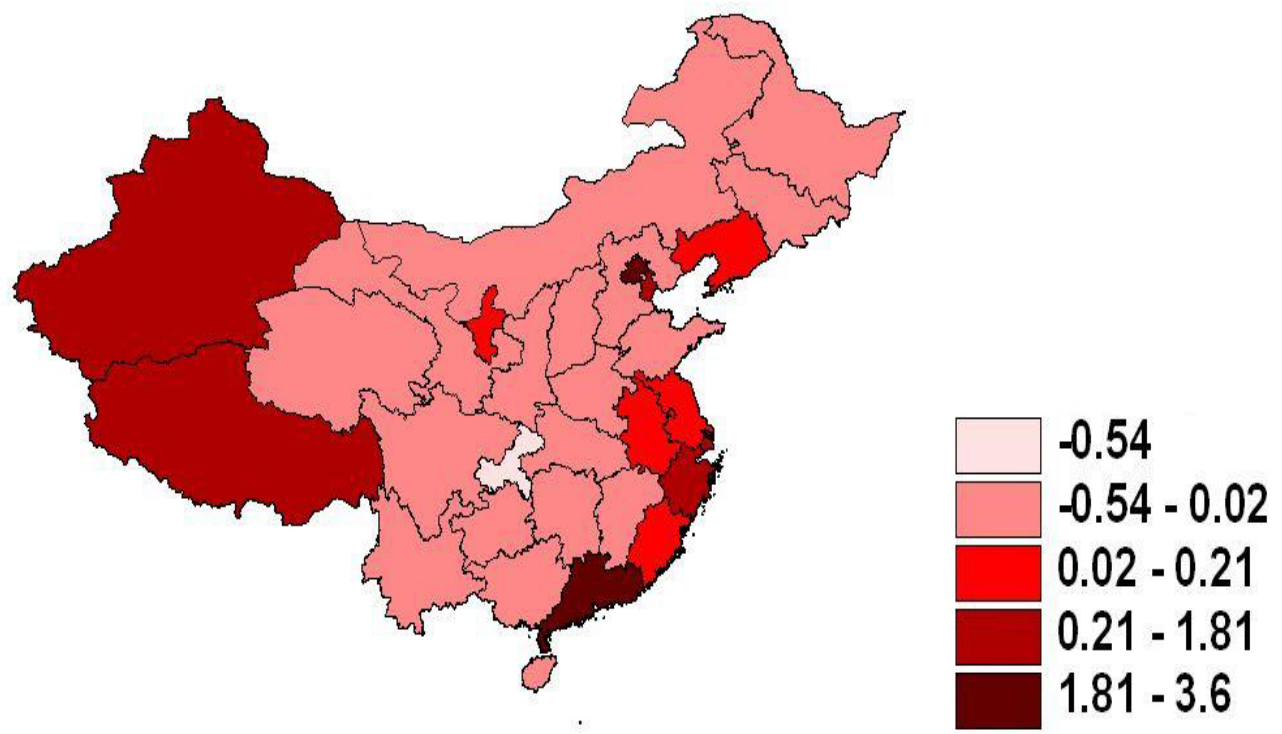

Source: The original data for the map are from China Statistical Yearbook 2005.

Southern Regional Science Association 2010. 
Figure 12 shows that the three coastal growth centers, i.e., the Pearl River Delta (mainly Guangdong Province), the Yangtze River Delta (including Shanghai, South Jiangsu Province and North Zhejiang Province), and the Beijing-Tianjin metropolitan area, have the greatest positive annual shares of net migration. The three ethnic autonomous regions, Xinjiang, Tibet, and Ningxia, also have relatively large shares of positive annual net migrants as a percentage of their total populations, but this is likely a result of policy incentives rather than one founded on free-market principles. The central government encourages highly-educated people to work in these ethnic autonomous regions. This strategy promotes the migration of "knowledge workers" into these regions to help strengthen their long-run economies. In return, these migrant "knowledge workers" are rewarded with extra economic benefits and job promotion. What remains unexplained is that Chongqing municipality, though an urbanized area in Central China, experiences negative net migration.

\subsection{Household Transition}

As demographic transition evolves, household size also shrinks significantly and the nuclear family replaces the traditional extended family. In China, a nuclear family is three people: father, mother, and child. The China Statistical Yearbook has a count of the number of households in each province, sizes ranging from one person up to ten people and above. The share of households in each province with at least four people is used as a threshold in this study.

Figure 13 shows that the coastal provinces, with the exception of Guangdong Province, generally have the lowest share of households with more than three people. Northeast China and Chongqing municipality also have low shares of this type of household. These anomalies may be attributed to their high levels of urbanization. In addition, although not coastal provinces, Sichuan Province and Inner Mongolia have rather low shares of big households.

\section{FIGURE 13. Percentage of Households with at Least Four People, 2004}

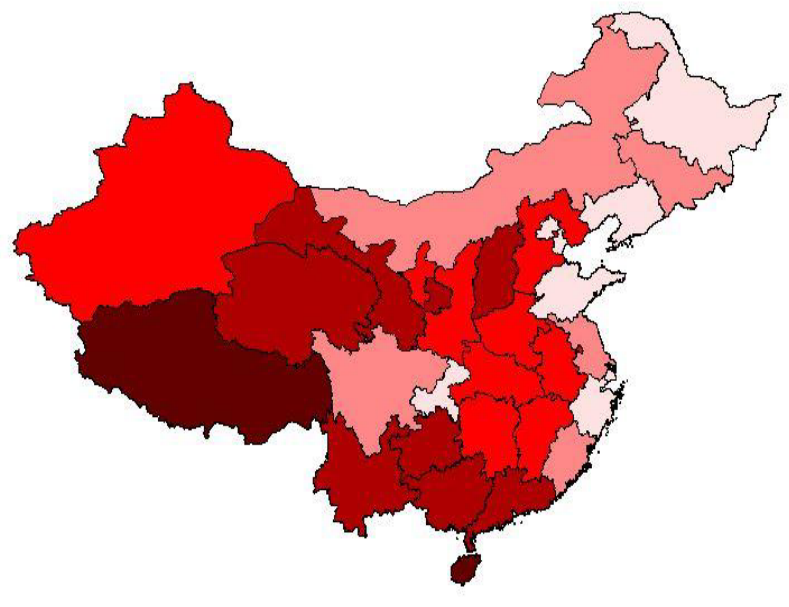


TABLE 4. Household Transition and Socio-economic Factors

\begin{tabular}{|c|c|c|c|c|c|c|}
\hline & \multicolumn{2}{|c|}{ (1) Income } & \multicolumn{4}{|c|}{ (2) Industrialization } \\
\hline & & & $(2 a)$ & & (2b) & \\
\hline & Coef. & Sig. & Coef. & Sig. & Coef. & Sig. \\
\hline W_household & -0.3860 & $* * *$ & & & & \\
\hline Urban income & 0.0053 & $* * *$ & & & & \\
\hline Rural income & -0.0167 & $* * *$ & & & & \\
\hline LQ primary industry & & & & & 28.9823 & $* * *$ \\
\hline LQ secondary industry & & & -15.5810 & $* * *$ & & \\
\hline LQ tertiary industry & & & -16.4928 & $* * *$ & & \\
\hline Constant & 61.9816 & & 74.7880 & $* * *$ & 13.9690 & $* * *$ \\
\hline Adjusted $R^{2}$ & 0.663 & & 0.520 & & 0.531 & \\
\hline
\end{tabular}

Regression analysis (see Table 4) finds that each 1,000 Yuan increase in rural residents' income is significantly associated with a 16.7 percentage point decrease in the share of households larger than a typical nuclear one in China. Urban residents' income again has the opposite effect after rural residents' income is controlled for, although the coefficient is small. This statistical relationship could result because the nuclear family is the dominant household type in urban areas regardless of income level, so what matters is the share of such households in rural areas. In wealthier rural areas, people are more likely to live in smaller households. Also, provinces with more secondary and tertiary industries but less primary industry tend to have fewer households with more than three people.

\section{CONCLUSIONS}

China's economic reform and opening-up policies were predicated upon a "growth center" approach. Thus, it initially gave priority to the coastal provinces, which enjoy natural location advantages for international trade. After three decades of the economic reform, China's least developed regions still wait for the anticipated "trickling-down” of income to arrive. Instead, it has been diffused more slowly than expected and the regional gap in incomes between the East and its hinterland, i.e., Central China, West China, and the Northeast, has grown. The interregional income gap has become associated with different socioeconomic characteristics of the core and periphery, which has led to their different expression in demographic transition.

This paper explores a broad array of spatial patterns in China's fertility transition, age transition, migration transition, and household transition. Mortality transition is left out because the pattern appears to be consistent across regions. Interprovincial maps of the regional pattern of demographic transition roughly follow a gradient of economic status, and regression analysis indicates that this pattern is more sensitive to rural areas' economic well-being rather than that of urban areas.

Southern Regional Science Association 2010. 
Major findings include:

(1) Socio-economic status influences the degree of compliance with the one-child policy and contributes to China's fertility transition. Urbanization level, rural residents' income, college education (especially that of females), and the level of industrialization as measured by location quotients of secondary and tertiary industries are positively related with the percentage of only-child population.

(2) The spatial pattern of life expectancy has roughly followed the gradient of economic growth. Rural residents' income explains the regional variation in life expectancy and youth dependency ratio.

(3) The "growth centers" already have higher population density, yet they are still experiencing intensive in-migration. Measurement using "hukou” can capture the in-migration of migrant workers, and the coastal area has the highest percentage of population without a local hukou. Specifically, higher urban residents' income and an industry mix skewed towards secondary and tertiary industries serve as the "pull” factors in migration of the semi-skilled labor.

(4) The nuclear family is a more prevailing household type in the coastal area. Rural residents' income and the industrialization level both have negative associations with the percentage of households with more than three people.

China's regional disparity in demographic transition can be interpreted as the epitome of China's development story. As Myrdal (1957) illustrates through the cumulative causation theory, existing regional income inequalities could snowball if left to unadulterated market forces unhampered by any policy interference. Although a developing country like China must inevitably run through a period of unbalanced development, it ought not to drift too far from interregional equity in its course to higher economic well-being. For instance, the selective nature of the migration transition, in the case of the migration of "knowledge workers" towards the urban core, tends to deprive the periphery of its best human talent. It is effectively a wedge that exacerbates the existing regional gap (Friedman 1966). The hinterland's slower progress in fertility transition also poses an obstacle to its hopes of closing the gap in per capita income, since the continued rise in population makes the need for technological advancement and, hence, productivity growth, less necessary. In this sense, the paper highlights certain "pressure points" where appropriate policy intervention could be applied to accelerate income diffusion processes and encourage achievement of a long-run spatial equilibrium. In fact, China's government has taken some measures, such as "the grand development of Western regions" and the "vitalizing traditional Northeast industrial base” programs to reduce regional income disparities. This could positively affect the future pace of the hinterland's demographic transition.

Several limitations of the paper should be addressed, however. First, some exceptions to the one-child policy may have distorted the patterns of regional demographic transition and their relationships with socio-economic characteristics. For instance, the share of population that is composed of minority ethnicities is positively correlated with birth rate with a coefficient of 0.65. This is partly due to the regulation relief that permits minorities to opt out of the one-child policy

Southern Regional Science Association 2010. 
and also partly a factor of the propensity for minority populations to live in provinces that are less developed. Clearly, a means of disentangling the effects of policy relief from those of socio-economic factors in the study of fertility transition must be further explored. Second, although the overall regional demographic transition pattern roughly follows a gradient of economic status, exceptions stand out time and time again, e.g., Guangdong Province, Northeast China, and Inner Mongolia. It is hoped that further study will employ other variables to better understand the root causes of these exceptions. Third, intraprovincial disparities in demographic transition between the urban and rural areas are not investigated in this paper: interpretations generated strictly from maps can mask such intraprovincial differences, although such pictures can be quite convincing. However, the feasibility of further study in this respect is currently limited by a lack of data, at least across rural and urban areas within provinces. Finally, the paper could have been more informative if panel data for provinces was used since it may have permitted Granger-causal inferences. Future research could also study each region's trend in demographic transition over the long term, which would reveal its link to the changing national economic paradigm.

\section{REFERENCES}

Bairoch, Paul. (1988) Cities and Economic Development. University of Chicago Press: Chicago, Illinois.

Becker, Gary S. (1981) A Treatise on the Family. Harvard University Press: Cambridge, Massachusetts.

Birdsall, Nancy and Dean T. Jamison. (1983) "Income and Other Factors Influencing Fertility in China,” Population and Development Review, 9, 651-675.

Caldwell, John C. (1978) “A Theory of Fertility: From High Plateau to Destabilization,” Population and Development Review, 4, 553-577.

. (1997) “The Global Fertility Transition: The Need for a Unifying Theory,” Population and Development Review, 23, 803-812.

China Statistical Yearbook 2005. (2005) Available at: http://www.stats.gov.cn/tjsj/ndsj/2005/ indexch.htm.

Cleland, John and German Rodriguez. (1988) "The Effect of Parental Education on Marital Fertility in Developing Countries,” Population Studies, 42, 419-442.

Coale, Ansley J. (1987) “Demographic Transition,” in John Eatwell, Murray Milgate, and Peter Newman, eds., The New Palgrave Dictionary of Economics. MacMillan Press: London.

Coale, Ansley J. and Chen S. Li. (1987) Basic Data on Fertility in the Provinces of China, 1940-1982. East-West Population Institute: Honolulu, HI.

Darrat, Ali F. and Yousif K. Al-Yousif. (1999) “On the Long-Run Relationship between Population and Economic Growth: Some Time Series Evidence for Developing Countries,” Eastern Economic Journal, 25, 301-305.

Southern Regional Science Association 2010. 
Dyson, Tim and Mike Murphy. (1985) “The Onset of Fertility Transition,” Population and Development Review, 11, 399-440.

Easterlin, Robert A. (1987) "Fertility,” in John Eatwell, Murray Milgate, and Peter Newman, eds., The New Palgrave: A Dictionary of Economics. MacMillan Press: London, pp. 302-308.

Edlund, Lena and Nils-Petter Lagerlof. (2006) "Individual versus Parental Consent in Marriage: Implications for Intra-Household Resource Allocation and Growth,” American Economic Review, 96, 304-307.

Ehrlich, Isaac and Hiroyuki Chuma. (1990) "A Model of the Demand for Longevity and the Value of Life Extension,” Journal of Political Economy, 98, 761-782.

Ehrlich, Isaac and Francis Lui. (1997) “The Problem of Population and Growth: A Review of Literature from Malthus to Contemporary Models of Endogenous Population and Endogenous Growth,” Journal of Economic Dynamics and Control, 21, 205-242.

Friedmann, John. (1966) Regional Development Policy: a Case Study of Venezuela. MIT Press: Cambridge, MA.

Galor, Oded. (2005) “From Stagnation to Growth: Unified Growth Theory,” in Philippe Aghion and Steven N. Durlauf, eds., Handbook of Economic Growth, Vol. 1, Part A. Elsevier: Amsterdam, pp. 171-293.

Galor, Oded and David N. Weil. (1999) "From Malthusian Stagnation to Modern Growth," American Economic Review, 89, 150-154.

- (2000) "Population, Technology and Growth: From the Malthusian Regime to the Demographic Transition,” American Economic Review, 110, 806-828.

Gasahl, Laurie. (2006) An Analysis of Factors Affecting China's Population Planning Program: Cases from Jiangsu and Jiangxi Provinces. Unpublished doctoral dissertation, Michigan State University.

Gould, Eric D., Omer Moav, and Avi Simhon. (2008) “The Mystery of Monogamy,” American Economic Review, 98, 333-357.

Grossman, Michael. (1972) The Demand for Health: A Theoretical and Empirical Investigation. Columbia University Press: New York.

Handwerker, W. Penn. (1986) “Culture and Reproduction: Exploring Micro/Macro Linkages,” in W. Penn Handwerker, ed., Culture and Reproduction: An Anthropological Critique of Demographic Transition Theory. Westview Press: Boulder, CO, pp. 1-29.

. (1989) Women's Power and Social Revolution: Fertility Transition in the West Indies. Sage Publications: Newbury Park, CA.

- (1991) "Women's Power and Fertility Transition: The Cases of Africa and the Caribbean,” Population and Environment, 13, 55-78.

Hazan, Moshe and Binyamin Berdugo. (2002) "Child Labor, Fertility, and Economic Growth,” The Economic Journal, 112, 810-828.

Southern Regional Science Association 2010. 
Hirschman, Albert O. (1958) The Strategy of Economic Development. Yale University Press: New Haven, CT.

Jayaraman, Tiru K. (1995) "Demographic and Socioeconomic Determinants of Contraceptive Use among Urban Women in the Melanesian Countries in the South Pacific: A Case Study of Port Vila Town in Vanuatu,” Asian Development Bank: Manila, Philippines.

Kalemli-Ozcan, Sebnem. (2002) "Does the Mortality Decline Promote Economic Growth?," Journal of Economic Growth, 7, 411-439.

Li, Godfrey J-K. (2005) The Influence of Women's Status on Fertility Behavior between Taiwan and China-A Multilevel Analysis. Doctoral Dissertation, Texas A\&M University.

Malthus, Thomas R. (1798) First Essay on Population. Reprints of economic classics, 1965. Augustus Kelley: New York.

Merli, M. Giovanna and Herbert L. Smith. (2002) "Has the Chinese Family Planning Policy Been Successful in Changing Fertility Preferences?,” Demography, 39, 557-572.

Micklin, Michael. (1969) "Urban Life and Differential Fertility: Specification of an Aspect of the Theory of the Demographic Transition,” Sociological Quarterly, 10, 480-500.

Myrdal, Gunnar. (1957) Economic Theory and Undeveloped Regions. Harper Torch Books: New York.

Poston, Dudley L., Jr. and Baochang Gu. (1987) “Socioeconomic Development, Family Planning, and Fertility in China," Demography, 24, 531-551.

Pritchett, Lant H. (1994) "Desired Fertility and the Impact of Population Policies," Population and Development Review, 20, 1-55.

Richardson, Harry W. (1978) "Growth-pole Analysis," Chapter 7 in Regional Economics. University of Illinois Press: Urbana, Illinois.

Sato, Yasuhiro and Kazuhiro Yamamoto. (2005) "Population Concentration, Urbanization, and Demographic Transition,” Journal of Urban Economics, 58, 45-61.

Schultz, T. Paul. (1985) "Changing World Prices, Women's Wages, and the Fertility Transition: Sweden, 1860-1910,” Journal of Political Economy, 93, 1126-1154.

Simon, Julian L. (1992) Population and Development in Poor Countries. Princeton University Press: Princeton, New Jersey.

Solow, Robert M. (1956) “A Contribution to the Theory of Economic Growth," Quarterly Journal of Economics, 70, 65-94.

Tien, H. Yuan. (1984) "Induced Fertility Transition: Impact of Population Planning on Socio-Economic Change in the People's Republic of China," Population Studies, 38, 385-400.

Weeks, John R. (2005) Population: An Introduction to Concepts and Issues. Wadsworth: Belmont, California.

World Bank. (2008) World Development Indicators 2008. Washington, D.C.

Southern Regional Science Association 2010. 


\section{APPENDIX TABLE. Definitions of Explanatory Variables}

\begin{tabular}{ll}
\hline \hline Variable name & Definition \\
\hline Urban income & Urban residents' annual personal income per capita, in Chinese Yuan \\
Rural income & Rural residents' annual personal income per capita, in Chinese Yuan \\
Urban population & Percentage of population that resides in urban area (\%) \\
LQ primary industry & Employment location quotient of the primary industry \\
LQ secondary industry & Employment location quotient of the secondary industry \\
LQ tertiary industry & Employment location quotient of the tertiary industry \\
College & Percentage of population 6 years and above that has college degree (\%) \\
College-Female & Percentage of female population 6 years and above that has college degree (\%) \\
College-Male & Percentage of male population 6 years and above that has college degree (\%) \\
Illiteracy rate & Percentage of population 15 years and above that is illiterate or quasi-illiterate (\%) \\
Illiteracy-Female & Percentage of female population 15 years and above that is illiterate or quasi-illiterate (\%) \\
Illiteracy-Male & Percentage of male population 15 years and above that is illiterate or quasi-illiterate (\%) \\
\hline \hline
\end{tabular}

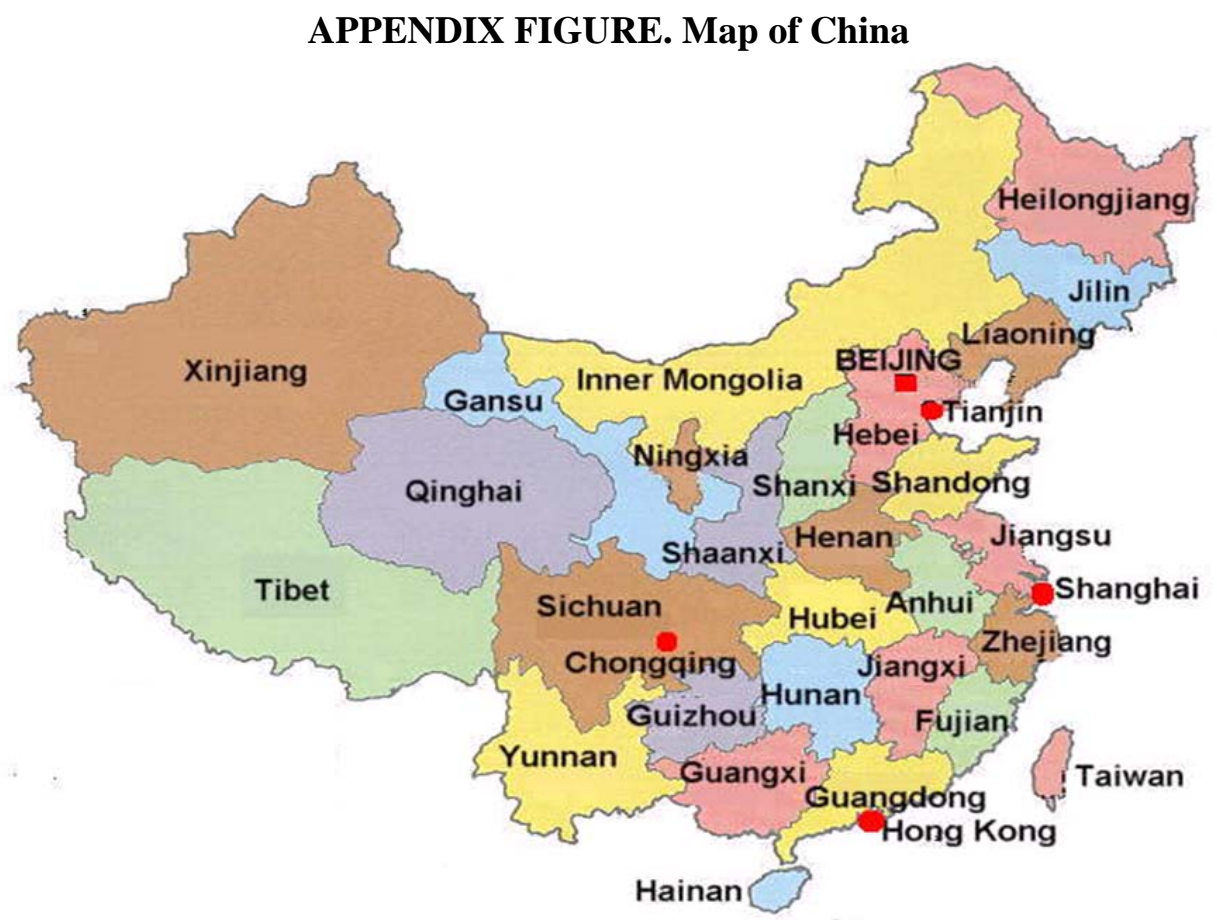

Southern Regional Science Association 2010. 